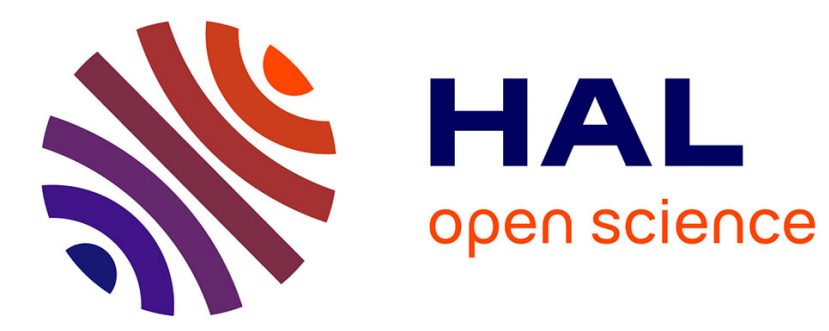

\title{
Cytogenetic and developmental toxicity of cerium and lanthanum to sea urchin embryos
}

\author{
Rahime Oral, Paco Bustamante, Michel Warnau, Antonello d'Ambra, \\ Giovanni Pagano
}

\section{- To cite this version:}

Rahime Oral, Paco Bustamante, Michel Warnau, Antonello d'Ambra, Giovanni Pagano. Cytogenetic and developmental toxicity of cerium and lanthanum to sea urchin embryos. Chemosphere, 2010, 81, pp.194-198. 10.1016/j.chemosphere.2010.06.057 . hal-00666446

\section{HAL Id: hal-00666446 https://hal.science/hal-00666446}

Submitted on 4 Feb 2012

HAL is a multi-disciplinary open access archive for the deposit and dissemination of scientific research documents, whether they are published or not. The documents may come from teaching and research institutions in France or abroad, or from public or private research centers.
L'archive ouverte pluridisciplinaire HAL, est destinée au dépôt et à la diffusion de documents scientifiques de niveau recherche, publiés ou non, émanant des établissements d'enseignement et de recherche français ou étrangers, des laboratoires publics ou privés. 
Cytogenetic and developmental toxicity of cerium and lanthanum to sea urchin embryos

\section{Rahime Oral ${ }^{1}$ Paco Bustamante ${ }^{2}$ Michel Warnau $^{2}$ Antonello D’Ambra $^{3}$ Giovanni Pagano ${ }^{4}$}

${ }^{1}$ Ege University, Faculty of Fisheries, TK-35100 Bornova, Izmir, Turkey

${ }^{2}$ La Rochelle University, Littoral, Environnement et Sociétés (LIENSs), UMR 6250, CNRS-

Université de La Rochelle, F-17042 La Rochelle Cedex 01, France

${ }^{3} 2^{\text {nd }}$ Naples University, Dept. Strategy and Quantitative Methods, I-81043 Capua (CE), Italy

${ }^{4}$ Federico II University, Dept. Biological Sciences, Section of Hygiene, I-80134 Naples, Italy

Giovanni Pagano ( $\bowtie)$

Federico II University, Department of Biological Sciences, Section of Hygiene,

Via Mezzocannone 16, I-80134 Naples, Italy

E-mail: gbpagano@tin.it

Tel.: 39-335-7907261 


\section{Abstract}

The aim of this study was to evaluate the toxicity of two rare earth elements (REE), cerium and lanthanum on sea urchin embryos and sperm. Sea urchin (Paracentrotus lividus) embryos were reared for $72 \mathrm{~h}$ in Ce(IV)- or La(III)-contaminated seawater at concentrations ranging from $10^{-8}$ to $10^{-5} \mathrm{M}$. Cleaving embryos (5 h post-fertilization) were submitted to cytogenetic analysis, scoring mitotic activity and a set of mitotic aberrations. Embryological analysis was carried out to determine percent developmental anomalies and/or embryonic mortality. P. lividus sperm were suspended in Ce(IV) or La(III) $\left(10^{-8}-10^{-5} \mathrm{M}\right)$ for $1 \mathrm{~h}$, and percent fertilized eggs were scored in cleaving embryos that were cultured up to pluteus stage to score any developmental defects. Embryos reared in $10^{-5} \mathrm{M} \mathrm{Ce}(\mathrm{IV})$ resulted in $100 \%$ embryonic mortality, whereas $10^{-5} \mathrm{M} \mathrm{La}(\mathrm{III})$ induced $100 \%$ developmental defects, without causing any embryonic mortality. A significant concentration-related mitotoxic effect and induction of mitotic aberrations were observed in Ce(IV)-exposed, but not in La(III)-exposed embryos, at concentrations ranging from $10^{-7} \mathrm{M}$ to $3 \times 10^{-6} \mathrm{M}$. Following sperm exposure, both Ce(IV) and La(III) induced a decrease in sperm fertilization success at the highest tested concentration $\left(10^{-5} \mathrm{M}\right)$. The offspring of Ce(IV)-exposed, but not of La(III)-exposed sperm displayed a significant concentration-related increase in developmental defects. The results may suggest adverse impacts in REE-exposed biota and warrant further studies of a more extended REE series.

Key words: rare earth elements; cerium; lanthanum; sea urchins; pluteus; fertilization; developmental defects; cytogenetic anomalies 


\section{Introduction}

A number of technological developments have led to the utilization of REE in a broad array of industrial processes (reviewed by Dickson, 2006). Along with their utilization, REE mining, extraction and manufacturing raise as yet scarcely investigated questions about their possible impact on both human and environmental health. In the case of marine environments, REE, like other anthropogenic contaminants, may be released from industrial wastewater effluents and affect both coastal waters and sediments, hence sedimentdwelling biota. Whereas dissolved REEs are reported to display very low concentrations in natural open seawater, i.e. typically in the $\mathrm{pg} \mathrm{L}^{-1}$ range (Bau et al., 1997; Wang and Yamada, 2007), they are effectively bioaccumulated by marine invertebrates such as squids or krill (Ichihashi et al., 2001; Palmer et al., 2006). Ce and La concentrations reported for these marine organisms range between 0.02 and $2 \mu \mathrm{gg}^{-1}$ dry wt., i.e. between 4 and 7 orders of magnitude the concentrations in surrounding waters. A recent study pointed out that REE bioaccumulation in two Nautilus species from Pacific Ocean islands (Vuanutu and New Caledonia), up to $1 \mu \mathrm{g} \mathrm{g}^{-1} \mathrm{Ce}$ and La in digestive gland, were related to specific environmental processes, such as volcanism or upwelling (Pernice et al., 2009). A much higher degree of REE bioaccumulation was reported in the scallop Chlamys varia from the Bay of Biscay (West France) that was suggested to be associated with release of REEcontaminated wastewater from industrial facilities located near La Rochelle, France (Bustamante and Miramand, 2005). That study showed that La concentrations reached up to $8 \mu \mathrm{g} \mathrm{g}^{-1}$ dry wt in the digestive gland of scallops from REE-contaminated areas, whereas La levels remained below $0.3 \mu \mathrm{g} \mathrm{g}^{-1}$ dry wt in this tissue from scallops collected in the control area not subjected to the industrial outputs. Therefore, releases of REE due to mining or 
industrial activities could enhance bioaccumulation levels and potentially produce adverse effects on marine organisms.

A relatively scarce database is currently available as to REE associated toxicity, especially for marine organisms. In the case of $\mathrm{Ce}$ and La, a major focus has been devoted to their implications in terms of counteracting or triggering oxidative stress, leading to apparently conflicting results. Indeed, both pro-oxidant and antioxidant actions were reported to be concentration-dependent outcomes (Wang et al., 2000; Gao et al., 2008), whereas other studies only reported antioxidant or, vice versa, pro-oxidant effects (Chen et al., 2004; Lin et al., 2006; Schubert et al., 2006; Kawagoe et al., 2008; Park et al., 2008; Xia et al., 2008).

A few published reports on Ce and/or La effects in marine organisms, to the best of our knowledge only focused on REE uptake in a marine diatom (Bingler et al., 1989), and REE bioaccumulation in some mollusks (e.g. Lobel et al., 1991; Ichihashi et al., 2001; Bustamante and Miramand, 2005; Pernice et al., 2009) and crustaceans (Palmer et al., 2006). Data describing the toxicity of Ce or La towards marine organisms, in particular their early life stages, were not found in the literature. On the other hand, cytological and cytogenetic effects of several REE (holmium, neodymium and praseodymium) were reported in Vicia faba root tips (Singh et al., 1997; Qu et al., 2004), raising the as yet open question about cytogenetic effects of other REE. The effects of lanthanum and of a REE mixture were investigated on seed germination, seedling growth, root growth and antioxidant metabolism in wheat (Triticum durum) and in duckweed (Lemna minor) and reported a concentrationrelated shift from hormesis to inhibition and changes in the levels of some antioxidants as indicators of stress (d'Aquino et al., 2009; Ippolito et al., 2009). In an attempt to shed some light on this largely unexplored field, we evaluated Ce(IV)- and La(III)-associated effects on developmental and/or cytogenetic toxicity of these REE on sea urchin embryos, on 
fertilization success of sea urchin sperm, and on offspring quality following Ce(IV) or La(III) sperm exposure. The sea urchin bioassay system comprehends a set of endpoints assessed on fertilization, mitotic activity and embryogenesis, and has been successfully utilized in an extended series of reports on individual agents (Pagano et al., 1983; Warnau et al., 1997) and on model or complex mixtures (Pagano et al., 1986, 1996, 2001, 2002; Guillou et al., 2000; Meriç et al., 2005; Oral et al., 2007).

This study provided straightforward evidence for Ce(IV)-associated toxicities toward all tested endpoints, whereas La(III) exerted a concentration-related developmental toxicity, yet lesser or no toxicity for the other endpoints within the tested concentration range (up to $10^{-5} \mathrm{M}$ ).

\section{Materials and Methods}

\subsection{Sea urchins}

Sea urchins (Paracentrotus lividus) were purchased from Le Gall aquaculture company (La Flotte en Ré, Charente-Maritime, France). Gametes were obtained and embryos were reared in natural filtered seawater (FSW) collected offshore (3.5\% salinity, $\mathrm{pH} 8.2)$ as reported previously (Pagano et al., 1986, 2001). Controls were run in FSW as triplicate blanks, and 2.5 $X 10^{-4} \mathrm{M} \mathrm{CdSO}_{4}$ as a positive control. The embryos were reared in $\mathrm{Ce}$ (IV) or $\mathrm{La}$ (III) from $\mathrm{CeO}_{2}$ and $\mathrm{La}_{2} \mathrm{O}_{3}$ stock solutions $\left(1 \mathrm{~g} \mathrm{~L}^{-1}\right.$, approx. $\left.7 \times 10^{-3} \mathrm{M}\right)$ dissolved in $0.1 \mathrm{~N} \mathrm{HNO}_{3}$. It should be pointed out that the final $\mathrm{HNO}_{3}$ concentrations $\left(10^{-3}-10^{-5} \mathrm{M}\right)$ were unable to cause any $\mathrm{pH}$ shift in seawater causing any effects on embryogenesis, mitotic activity or fertilization (Pagano et al., 1985); thus no acid control was used. Embryo exposures to Ce(IV) or La(III) were performed throughout embryogenesis, starting from zygotes (10 min post-fertilization) up to the pluteus larval stage ( $72 \mathrm{~h}$ post-fertilization) by incubating the embryos at $18 \pm 1^{\circ} \mathrm{C}$; 
experiments were run for a total of 12 replicates. A series of experiments was performed on P. lividus sperm, by suspending a $50-\mu \mathrm{L}$ sperm pellet for $1 \mathrm{~h}$ in $30 \mathrm{~mL} \mathrm{FSW}$ containing Ce(IV) or La(III); thereafter, $50-\mu \mathrm{L}$ of sperm suspension were used to inseminate $10 \mathrm{~mL}$ untreated eggs ( 50 eggs $\left.\mathrm{mL}^{-1}\right)$.

\subsection{Embryological analysis}

Embryological analysis was performed on living plutei immobilized in 10-4 M chromium sulfate 10 min prior to observation, approx. $72 \mathrm{hrs}$ after fertilization (Pagano et al. 1986). In each treatment schedule, the first 100 plutei were scored for the percentages of: 1) normal larvae $(N) ; 2$ ) retarded larvae $(R$, size $<1 / 2 N)$; 3) malformed larvae (P1), mostly affected in skeletal differentation; 4) embryos/larvae unable to attain the pluteus stage (P2), i.e. abnormal blastulae or gastrulae, and 5) dead (D) embryos or larvae. Total developmental defects were scored as $(D D=P 1+P 2)$.

\subsection{Cytogenetic analysis}

Cytogenetic analysis was carried out on 30 cleaving embryos 5 hrs post-fertilization from four cultures in each treatment schedule and triplicate controls (each in quadruplicate cultures) amounted to a total of 12 control cultures. The embryos were fixed in Carnoy's fluid $5 \mathrm{hr}$ after fertilization, and stained by acetic carmine (Pagano et al., 2001). The measured endpoints were both quantitative and morphological abnormalities. Quantitative parameters included: a) mean number of mitoses per embryo (MPE); b) percent interphase embryos (IE), lacking any active mitoses, and c) metaphase:anaphase ratio (M/A). The frequencies of morphologic abnormalities were scored as: a) anaphase bridges (B); b) lagging chromosomes (LC); c) acentric fragments (AF); d) scattered chromosomes (SC); e) multipolar 
spindles (MS); f) total mitotic aberrations per embryo (TMA) and g) percent embryos having $\geq 1$ mitotic aberrations $[E(A b+)]$.

\subsection{Sperm bioassays}

Following a 1-h sperm pretreatment, fertilization success was measured as percent fertilized eggs or fertilization rate (FR) on live cleaving embryos 1 to 3 hrs post-fertilization. Thereafter, the embryos were cultured up to pluteus stage and scored for developmental defects as above described in order to evaluate the effects, if any, of sperm exposure on offspring quality.

Each observation was carried out blind on random-tagged specimens by trained readers.

\subsection{Statistical analysis}

The effects of $\mathrm{Ce}(\mathrm{IV})$ and of $\mathrm{La}(\mathrm{III})$ on the various endpoints were evaluated statistically using the Student's t-test, after applying the average square root transformation in order to normalize distributions. Those variables which were unsuitable for a parametric approach, i.e. $\% \mathrm{IE}, \% \mathrm{E}(\mathrm{Ab}+)$, and $\mathrm{M} / \mathrm{A}$, were evaluated with non-parametric tests, i.e. chi-square test, and Mann-Whitney U-test, respectively. The presence of several simultaneous comparisons required the use of multiple-comparison methods to correctly evaluate the level of statistical significance (Hocking, 1996). Data analysis was carried out using the SPSS 17 for Windows statistical software.

\section{Results}

\subsection{Embryo bioassays: developmental and cytogenetic toxicity}


By rearing P. lividus embryos in Ce(IV) or La(IV) (10-8 to 10-5 M), a concentration-related increase in developmental defects was observed up to micromolar levels of either Ce(IV) or $\mathrm{La}(\mathrm{III})$, as shown in Figure 1. However, the highest tested concentration, $10-5 \mathrm{M}$, resulted in $100 \%$ early embryonic (pre-hatch) mortality in Ce(IV)-exposed embryos (EC50 $=1.9 \times 10^{-6}$ M),, whereas La(III)-exposed embryos, at the same concentration, underwent $100 \%$ developmental defects (malformations or pre-larval arrest), with EC50 $=6.0 \times 10^{-6} \mathrm{M}$, without causing embryonic mortality (Fig. 1).

Cytogenetic analysis of Ce(IV)-exposed embryos showed concentration-related toxicity to mitotic activity as decreasing mitoses per embryo (MPE) in the micromolar range, as shown in Fig. 2, whereas no decrease in mitotic activity was detected in La(III)-exposed embryos. The same held true for the induction of mitotic aberrations, as\% embryos with P1 aberrations $[E(A b+)]$ increased to $31.7 \pm 12.3 \%$ following exposure to $\mathrm{Ce}(\mathrm{IV})\left(1-3 \times 10^{-6} \mathrm{M}\right)$, but not to $\mathrm{La}(\mathrm{III})$ at the same concentration $(6.7 \pm 2.7 \%)$ and vs. controls $(8.6 \pm 7.8 \%)(\mathrm{p}<$ 0.02), as shown in Fig. 3. When the different aberration patterns were considered, a significant excess of multipolar spindles (MS, an otherwise rare aberration) was detected in Ce(IV)-exposed embryos, as shown in Table 1, whereas the corresponding values in La(III)exposed embryos overlapped with control data. The other quantitative and morphologic mitotic anomalies were consistent with the data reported in Figs. 2 and 3, and in Table 1 (data not shown).

\subsection{Sperm Bioassays: fertilization success and offspring quality}

Significant inhibition of fertilization rate (FR) was observed only when P. lividus sperm were exposed to the highest tested concentration $\left(10^{-5} \mathrm{M}\right)$ of either $\mathrm{Ce}(\mathrm{IV})$ or $\mathrm{La}(\mathrm{III})$, as shown in Fig. 4. Offspring larvae from sperm exposed to Ce(IV) or La(III) displayed sharply different 
patterns of concentration-related developmental defects. As shown in Fig. 5, the offspring of sperm exposed to $10^{-5} \mathrm{M} \mathrm{Ce}(\mathrm{IV})$ displayed $100 \%$ larval or embryonic abnormalities (EC50 = $\left.2.8 \times 10^{-6} \mathrm{M}\right)$, whereas no increase in developmental defects was detected in the offspring of La(III)-exposed sperm at the same $10^{-5} \mathrm{M}$ level.

\section{Discussion}

Very few studies reported on REE concentrations in the tissues of marine invertebrates (Lobel et al., 1991; Ichihashi et al., 2001; Bustamante and Miramand, 2005; Palmer et al., 2006; Pernice et al., 2009). It is recognized that REE bioaccumulate in marine biota up to concentrations in the ppm range (Bustamante and Miramand, 2005). However, Ce(IV)- and La(III)-induced toxic effects have not been demonstrated so far in marine organisms and, namely, in the early life stages of the echinoid $P$. lividus. The results pointed to multiparameter effects of $\mathrm{Ce}(\mathrm{IV})\left(10^{-6}-10^{-5} \mathrm{M}\right)$ to $P$. lividus embryogenesis, including cytogenetic aberrations, developmental arrest and embryotoxicity. In contrast, La(III)-exposed embryos displayed $100 \%$ developmental defects when reared in $10^{-5} \mathrm{M} \mathrm{La}(\mathrm{III})$. However, neither cytogenetic anomalies nor embryonic mortality were observed in La(III)-exposed embryos. Analogous differences were detected in the outcomes of sperm bioassays; both Ce(IV) and La(III) exerted a moderate loss of fertilization success on sperm exposed to the highest tested concentration $\left(10^{-5} \mathrm{M}\right)$ of either agent. However, adverse effects in the offspring were only detected following exposure to $\mathrm{Ce}(\mathrm{IV})$, not to $\mathrm{La}(\mathrm{III})$. Together, these differences in toxicity patterns between Ce(IV) and La(III) may suggest further differences in the toxicities of other REE. In view of achieving an overall evaluation of the environmental impacts of different REE, systematic comparative investigations are warranted, in the attempt to fill the present information gap. 
The widespread and growing industrial uses of REE imply a current and increasing pervasiveness of these elements (Dickson, 2006), hence their potential impact toward environmental and human health. Rare earth/nitrate mixtures are used as fertilizers in China with the main components being lanthanum, cerium, praseodymium and neodymium (Tribe et al., 1990). REE are also released by mining activities from gold and uranium mining ores (Noller, 1991, 1994). Some data in the literature reported that REE affect cell division in plant tissues (d'Aquino et al., 2009). Lanthanum nitrate and a mixture of REE nitrates induced a decrease in the mitotic index of $T$. durum roots at millimolar concentrations. Mitotic anomalies were found in T. durum tissues treated with lanthanum nitrate such as the presence of dividing cells were in prophase, without other mitotic figures, with chromatin condensation and absence of nucleoli. The authors also indicated a more severe effect of the REE mixture compared to La(III) that could suggest a role of cerium in the process or a synergistic inhibitory effect of La and Ce, the main components of the REE mixture utilized in the assays (d'Aquino et al., 2009; Tommasi, personal communication).

A relatively scarce literature is available from in vitro and animal studies, and scanty reports are available on the effects of REE exposures in humans (Knight, 1994; McDonald et al., 1995; Hirano and Suzuki, 1996; Nakamura et al., 1997; Barry and Meehan, 2000). Studies have reported that human lung cells exposed to $\mathrm{Ce}$ nanoparticles (nanoCe) undergo apoptotic cytotoxicity and pro-oxidant effects, including increased formation of reactive oxygen species (ROS) and decreased GSH levels (Lin et al., 2006; Park et al., 2008). However, also cardioprotective effects were induced by nanoCe in mouse cardiomyopathy (Niu et al., 2007).

NanoCe was tested in four aquatic biota, Pseudokirchneriella subcapitata, Daphnia magna, Thamnocephalus platyurus, and Danio rerio embryos. No acute toxicity was exerted by 
nanoCe up to test concentrations of $200-1000 \mathrm{mg} \mathrm{L}^{-1}$. Significant chronic toxicity to $P$. subcapitata was observed with 10\% effect concentrations (EC10) between 2.6 and $5.4 \mathrm{mg} \mathrm{L}^{-1}$ (van Hoecke et al., 2009). Early studies reported that some REE (Ce, La and Nd), when administered to pregnant mice, decreased birth weight and litter size, yet without teratogenic effects (d'Agostino et al., 1982; Abramczuk, 1985; reviewed by Hirano and Suzuki, 1996). Recent in vivo studies reported on REE-induced adaptive responses including metallothionein and GSH upregulation, immune function in suckling mice (Liu et al., 2002), and decrease of pro-inflammatory cytokines, as TNF-a, IL-1b, and IL-6 (Kawagoe et al., 2008; Lin et al., 2006; Liu et al., 2006). Human exposures to Ce, La and Nd were reported to induce pneumoconiosis (McDonald et al., 1995; reviewed by Hirano and Suzuki, 1996) and to affect liver function (Zhu et al., 2005).

Altogether, one may foresee that forthcoming systematic studies will focus on a broader array of REE in order to evaluate their comparative toxicities in a number of marine, freshwater and terrestrial organisms, and will prompt further studies of REE toxicity in environmental and human health effects.

\section{Conclusions}

Both Ce(IV) and La(III) affect sea urchin embryogenesis at concentrations in the micromolar range. Cerium, but not lanthanum, induced cytogenetic anomalies by both decreasing mitotic activity and by inducing specific mitotic aberrations. These results both suggest analogous damage to early life stages of other organisms and prompt further investigations on broader sets of REE. Only minor effects on sperm were detected in terms of lowering fertilization success; hence, confining $\mathrm{Ce}$ and La toxicity evaluation to spermiotoxicity testing 
might provide misleading safety assessment. The observation of offspring damage following sperm exposure to Ce but not to La warrants further investigations in other bioassay models.

\section{Acknowledgments}

Thanks are due to Prof. Franca Tommasi (Bari University) for reviewing this manuscript.

\section{References}

Abramczuk JW (1985) The effects of lanthanum chloride on pregnancy in mice and on preimplantation mouse embryos in vitro. Toxicology 34:315-320

Barry MJ, Meehan BJ (2000) The acute and chronic toxicity of lanthanum to Daphnia carinata. Chemosphere 41:1669-1674

Bau M, Peter Möller P, Dulski P (1997) Yttrium and lanthanides in eastern Mediterranean seawater and their fractionation during redox-cycling. Mar Chem 56:123-131

Bingler LS, Byrne RH, Vargo GA, Tomas CR (1989) Rare earth element uptake by the marine diatom Skeletonema costatum. Chem Speciation Bioavailability 1:103-110

Bustamante P, Miramand P (2005) Subcellular and body distributions of 17 trace elements in the variegated scallop Chlamys varia from the French coast of the Bay of Biscay. Sci Tot Environ 337:59-73

Chen SA, Zhao B, Wang X, Yuan X, Wang Y (2004) Promotion of the growth of Crocus sativus cells and the production of crocin by rare earth elements. Biotechnol Lett 26:27-30

D'Agostino RB, Lown BA, Morganti JB, Massaro EJ (1982) Effects of in utero or suckling exposure to cerium (citrate) on the postnatal development of the mouse. J Toxicol Environ Health 10:449-458

d'Aquino L, de Pinto MC, Nardi L, Morgana M, Tommasi F (2009) Effect of some light rare earth elements on seed germination, seedling growth and antioxidant metabolism in Triticum durum. Chemosphere 75:900-905

Dickson E (2006) Rare earths. www.resourceworld.com, pp 1-20 
Gao QH, Wang XF, Shi QH, Yang FJ, Wei M (2008) Effects of lanthanum on the plant growth and leaf anti-oxidative enzyme activities of cucumber seedlings under nitrate stress. Ying Yong Sheng Tai Xue Bao 19:976-980 (in Chinese)

Guillou M, Quiniou F, Huart B, Pagano G (2000) Comparison of embryonic development and metal contamination in several populations of the sea urchin Sphaerechinus granularis (Lamarck) exposed to anthropogenic pollution. Arch Environ Contam Toxicol 39:337344

Hirano S, Suzuki KT (1996) Exposure, metabolism, and toxicity of rare earths and related compounds. Environ Health Perspect 104 (Suppl 1):85-95

Ichihashi H, Kohno H, Kannan K, Tsumura A, Yamasaki S-I (2001) Multielemental analysis of purpleback flying squid using high resolution inductively coupled plasma-mass spectrometry (HR ICP-MS). Environ Sci Technol 35:3103-3108

Ippolito MP, Fasciano C, d'Aquino L, Morgana M, Tommasi F (2009) Responses of antioxidant systems after exposition to rare earths and their role in chilling stress in common duckweed (Lemna minor L.): A defensive weapon or a boomerang? Arch Environ Contam Toxicol doi:10.1007/s00244-009-9340-9

Kawagoe M, Ishikawa K, Wang SC, Yoshikawa K, Arany S, Zhou XP, Wang JS, Ueno Y, Koizumi $\mathrm{Y}$, Kameda T, Koyota S, Sugiyama T (2008) Acute effects on the lung and the liver of oral administration of cerium chloride on adult, neonatal and fetal mice. J Trace Elem Med Biol 22:59-65

Knight AL (1994) The Rare Earths. In: Zenz C, Dickerson OB, Horvath EP, Jr (eds) Occupational Medicine, $3^{\text {rd }}$ edn. Mosby-Year Book, Inc., St. Louis, pp 572-576

Lin W, Huang YW, Zhou XD, Ma Y (2006) Toxicity of cerium oxide nanoparticles in human lung cancer cells. Int J Toxicol 25:451-457

Liu Z, Lei Z, Wei X, Xue B (2002) The effects of exposure to rare earth $\left(\mathrm{NO}_{3}\right)_{3}$ on the immune function of mice offspring via milk. Zhonghua Yu Fang Yi Xue Za Zhi 36:394-397

Lobel PB, Longerich HP, Jackson SE, Belkhode SP (1991) A major factor contributing to the high degree of unexplained variability of some elements concentrations in biological tissue: 27 elements in 5 organs of the mussel Mytilus as a model. Arch Environ Contam Toxicol 21:118-125 
McDonald JW, Chio AJ, Sheehan CE, Bernhardt PF, Roggli VL (1995) Rare earth (cerium oxide) pneumoconiosis: Analytical scanning electron microscopy and literature review. Mod Pathol 8:859-865

Meriç S, De Nicola E, laccarino M, Gallo M, Di Gennaro A, Morrone G, Warnau M, Pagano G (2005) Effluent toxicity in a leather tanning wastewater treatment plant in sea urchins and in marine microalgae. Chemosphere 61:208-217

Nakamura Y, Tsumura Y, Tonogai Y, Shibata T, Ito Y (1997) Differences in behavior among the chlorides of seven rare earth elements administered intravenously to rats. Fundam Appl Toxicol 37:106-116

Niu J, Azfer A, Rogers LM, Wang X, Kolattukudy PE. (2007) Cardioprotective effects of cerium oxide nanoparticles in a transgenic murine model of cardiomyopathy. Cardiovasc Res $1 ; 73: 549-559$

Noller BN (1991) Non-radiological contaminants from uranium mining and milling at ranger, Jabiru, Northern territory, Australia. Environ Monit Assess 19:383-400

Noller BN (1994) The identification of constituents in waste waters from gold mining using ICP-MS. Int J Surface Mining Reclam Environ 8:95-99

Oral R, Meriç S, De Nicola E, Petruzzelli D, Della Rocca C, Pagano G (2007) Multi-species toxicity evaluation of a chromium-based leather tannery wastewater. Desalination 211:48-57

Palmer AS, Snape I, Stark JS, Johnstone GJ, Townsend AT (2006) Baseline metal concentrations in Paramoera walkeri from East Antarctica. Mar Pollut Bull 52:14411449

Pagano G, Esposito A, Bove P, de Angelis M, Rota A, Giordano GG (1983) The effects of hexavalent and trivalent chromium on fertilization and development in sea urchins. Environ Res 30:442-452

Pagano G, Cipollaro M, Corsale G, Esposito A, Ragucci E, Giordano, GG. (1985) pH-induced changes in mitotic and developmental patterns in sea urchin embryogenesis. I. Exposure of embryos. Teratog Carcinog Mutagen 5:101-122

Pagano G, Cipollaro M, Corsale G, Esposito A, Ragucci E, Giordano GG, Trieff NM (1986) The sea urchin: Bioassay for the assessment of damage from environmental contaminants. In: Cairns J, Jr (ed) Community toxicity testing. Association for Standard Testing and Materials, Philadelphia, pp 67-92 
Pagano G, His E, Beiras R, De Biase A, Korkina LG, laccarino M, Oral R, Quiniou F, Warnau M, Trieff NM (1996) Cytogenetic, developmental and biochemical effects of aluminum, iron and their mixture in sea urchins and mussels. Arch Environ Contam Toxicol 31:466-474

Pagano G, Korkina LG, laccarino M, De Biase A, Deeva IB, Doronin YK, Guida M, Melluso G, Meriç S, Oral R, Trieff NM, Warnau M (2001) Developmental, cytogenetic and biochemical effects of spiked or environmentally polluted sediments in sea urchin bioassays. In: Garrigues P, Walker $\mathrm{CH}$, Barth $\mathrm{H}$ (eds) Biomarkers in marine ecosystems: A practical approach. Elsevier, Amsterdam, pp 85-129

Pagano G, De Biase A, Doronin YK, laccarino M, Meriç S, Petruzzelli D, Tünay O, Warnau M, Trieff NM (2002) Bauxite manufacturing residues from Gardanne (France) and Portovesme (Italy) exert different patterns of pollution and toxicity to sea urchin embryos. Environ Toxicol Chem 21:1272-1278

Park EJ, Choi J, Park YK, Park K (2008) Oxidative stress induced by cerium oxide nanoparticles in cultured BEAS-2B cells. Toxicology 245:90-100

Pernice M, Boucher J, Boucher-Rodoni R, Joannot P, Bustamante P (2009) Comparative bioaccumulation of trace elements between Nautilus pompilius and Nautilus macromphalus (Cephalopoda: Nautiloidea) from Vanuatu and New Caledonia. Ecotoxicol Environ Saf 72:365-371

Qu A, Wang CR, Bo J (2004) Research on the cytotoxic and genotoxic effects of rare-earth element holmium to Vicia faba. Yi Chuan 26:195-201 (in Chinese)

Schubert D, Dargusch R, Raitano J, Chan SW (2006) Cerium and yttrium oxide nanoparticles are neuroprotective. Biochem Biophys Res Commun 342:86-91

Singh AC, Pandey RB, Bharti M, Jha AM (1997) Cytological effects of two rare earth compounds on the root tip cells of Vicia faba L. J Environ Biol 18:27-31

Tribe DE, Robards KH, Reghenzani JR, Asher CJ (1990) Rare earth in Chinese agriculture. Report to the Australian Academy of Technological Sciences and Engineering, Victoria.

Tsai YY, Oca-Cossio J, Agering K, Simpson NE, Atkinson MA, Wasserfall CH, Constantinidis I, Sigmund W (2007) Novel synthesis of cerium oxide nanoparticles for free radical scavenging. Nanomed 2:325-332

van Hoecke K, Quik JK, Mankiewicz-Boczek J, De Schamphelaere KAC, Elsaesser A, van der Meeren P, Barnes C, McKerr G, Howard CV, van de Meent D, Rydzyński K, Dawson KA, 
Salvati A, Lesniak A, Lynch I, Silversmit G, de Samber B, Vincze L, Janssen CR (2009) Fate and effects of $\mathrm{CeO}_{2}$ nanoparticles in aquatic ecotoxicity tests. Environ Sci Technol $43: 4537-4546$

Wang Y, Zhang M, Wang X (2000) Population growth responses of Tetrahymena shanghaiensis in exposure to rare earth elements. Biol Trace Elem Res 75:265-275

Wang Z-L, Yamada M (2007) Geochemistry of dissolved rare earth elements in the Equatorial Pacific Ocean. Environ Geol 52:779-787

Warnau M, laccarino M, De Biase A, Temara A, Jangoux M, Dubois Ph, Pagano G (1997) Spermiotoxicity and embryotoxicity of heavy metals in the echinoid Paracentrotus lividus. Environ Toxicol Chem 15:1931-1936

Xia T, Kovochich M, Liong M, Mädler L, Gilbert B, Shi H, Yeh JI, Zink JI, Nel AE (2008) Comparison of the mechanism of toxicity of zinc oxide and cerium oxide nanoparticles based on dissolution and oxidative stress properties. ACS Nano 2:2121-2134

Zhu W, Xu S, Shao P, Zhang H, Wu D, Yang W, Feng J, Feng $L$ (2005) Investigation on liver function among population in high background of rare earth area in South China. Biol Trace Elem Res 104:1-8 


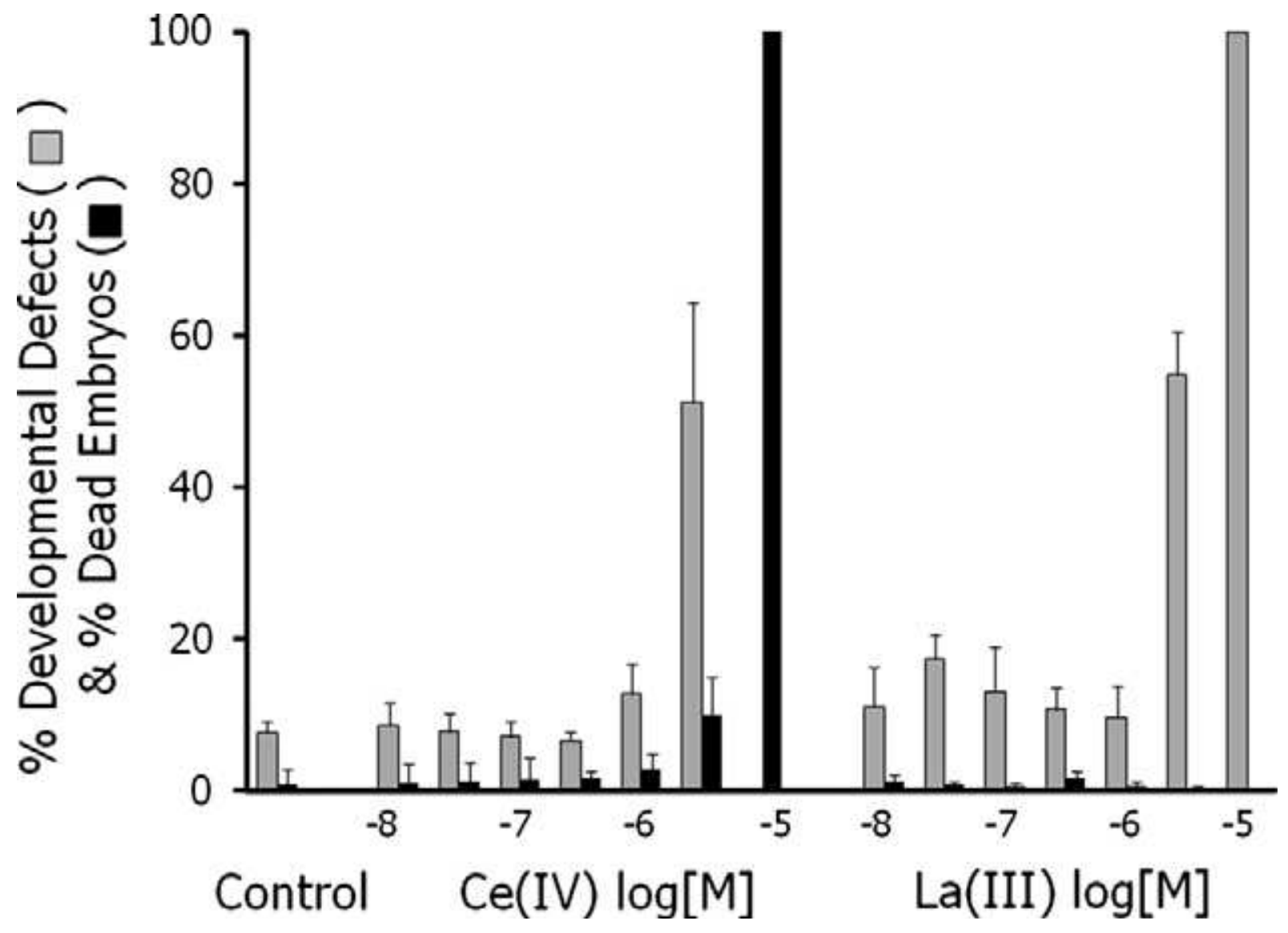

Fig. 1 Percent rates of developmental defects and mortality in P. lividus embryos/larvae reared in Ce(IV)- or La(III)-contaminated seawater. (*) $3 \times 10^{-6} \mathrm{M} \mathrm{Ce(IV)} \mathrm{exposure}$ resulted in highly significant embryotoxicity both vs. controls $(p=0)$ and vs. $\mathrm{La}(\mathrm{III})$ exposure ( $p<0.02$ ), up to $10^{-5} \mathrm{M} \mathrm{Ce}(\mathrm{IV})$ resulting in $100 \%$ embryonic mortality. 


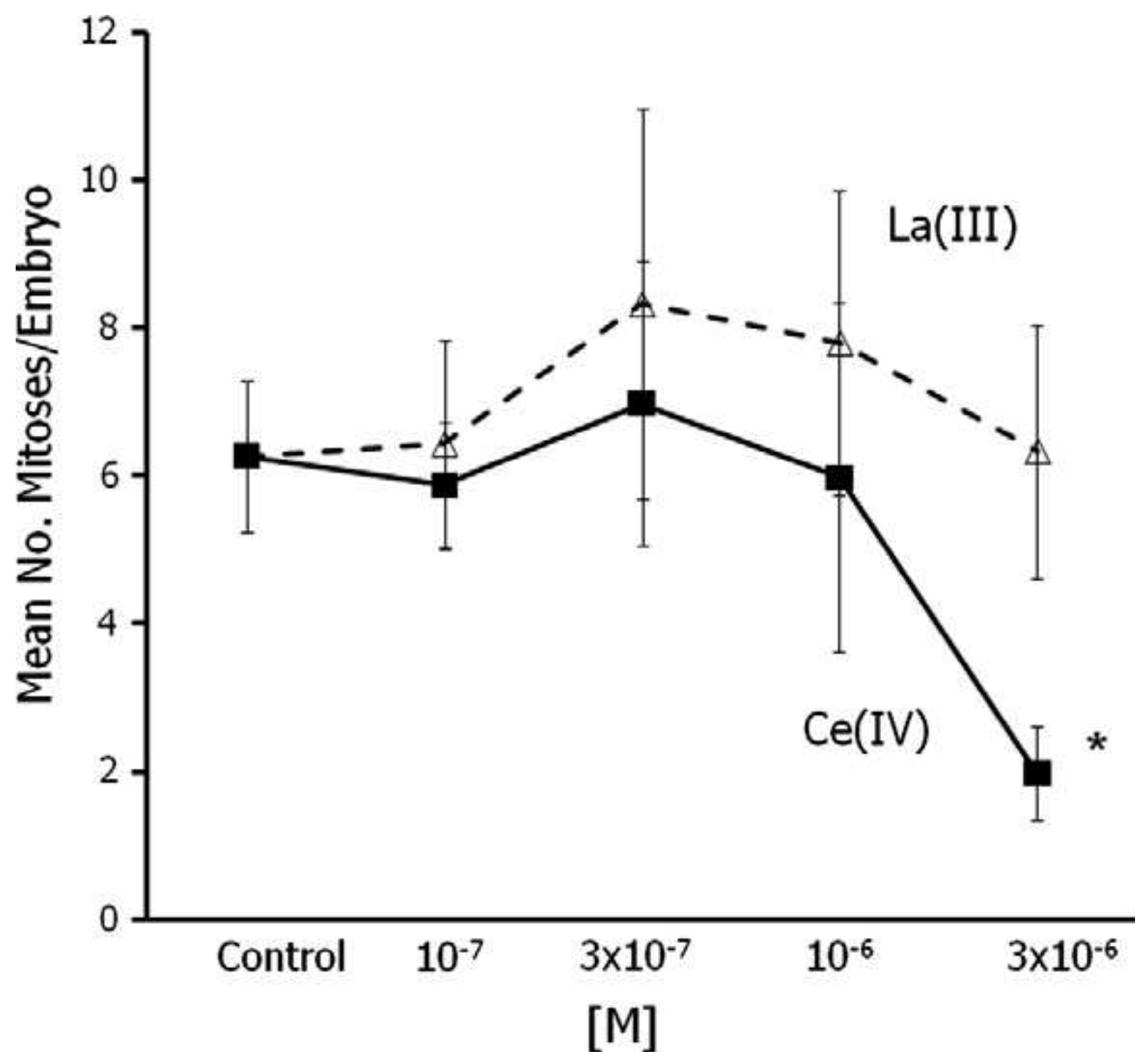

Fig. $2 \mathrm{Ce}(\mathrm{IV})$, not La(III) exposure of cleaving embryos resulted in a concentration-related decrease in mitotic activity. $\left({ }^{*}\right) p<0.02$. 


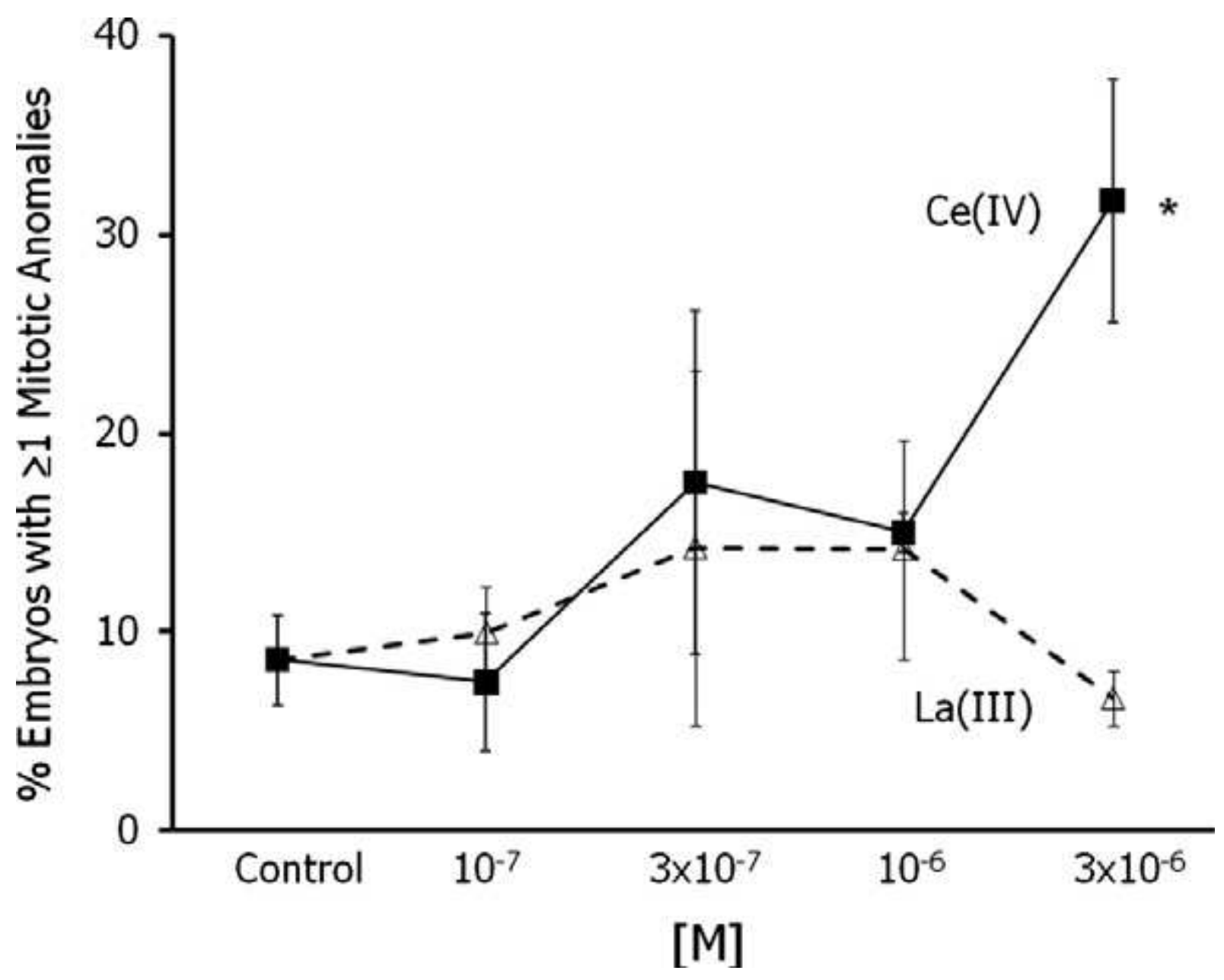

Fig. 3 Concentration-related increase in Ce(IV)-induced mitotic aberrations in P. lividus embryos $\left(^{*}\right)$ [p $<0.01$ at $\left.3 \times 10^{-6} \mathrm{M} \mathrm{Ce}(\mathrm{IV})\right]$. No effects were detected in La(III)exposed embryos. 


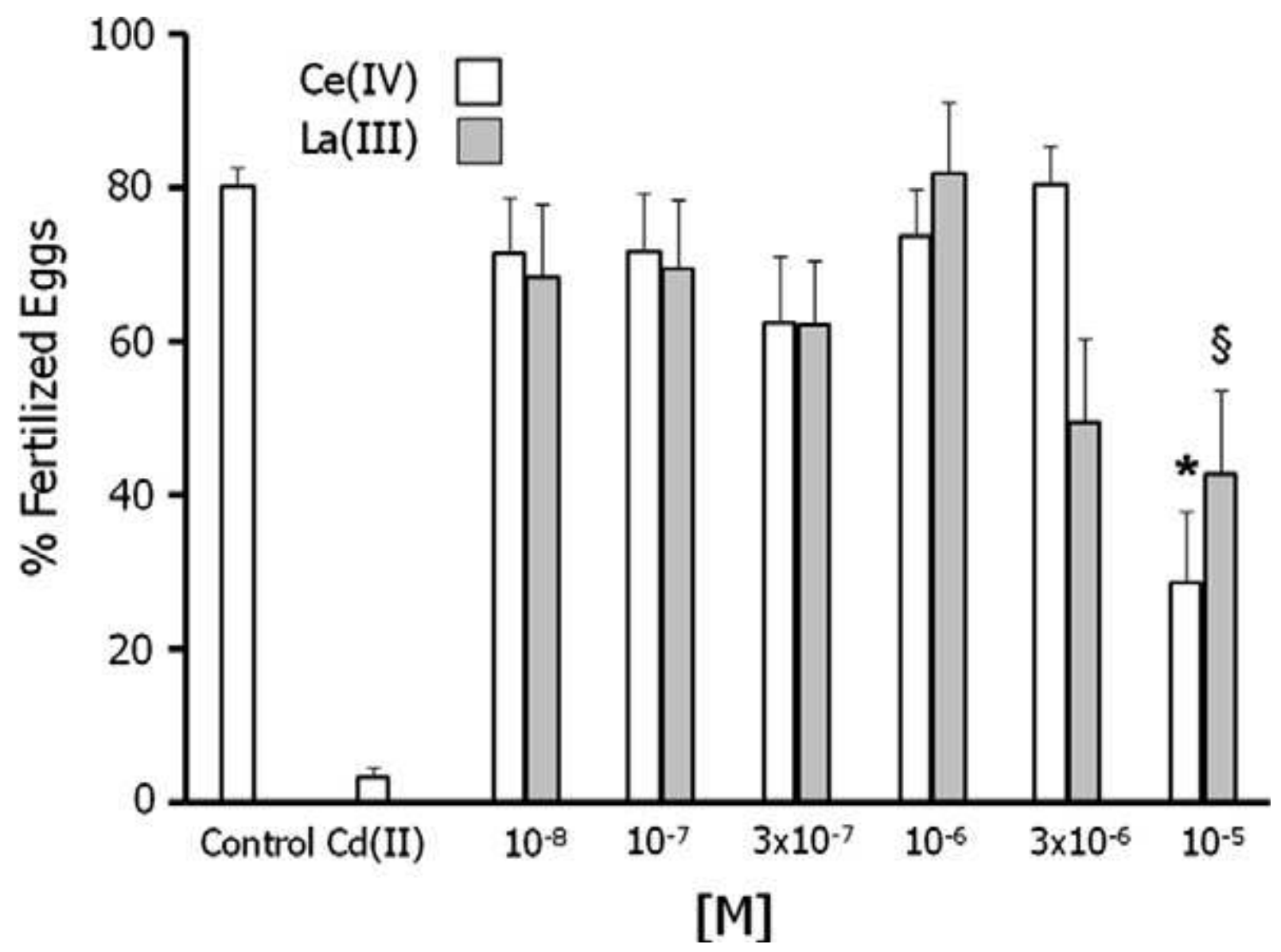

Fig. 4 Fertilization rate following sperm exposure Ce(IV) or La(III) was significantly inhibited by $10^{-5} \mathrm{M} \mathrm{Ce}(\mathrm{IV})(* \mathrm{p}<0.02)$ and by $10^{-5} \mathrm{M} \mathrm{La}(\mathrm{III})(\S \mathrm{p}<0.05)$. 


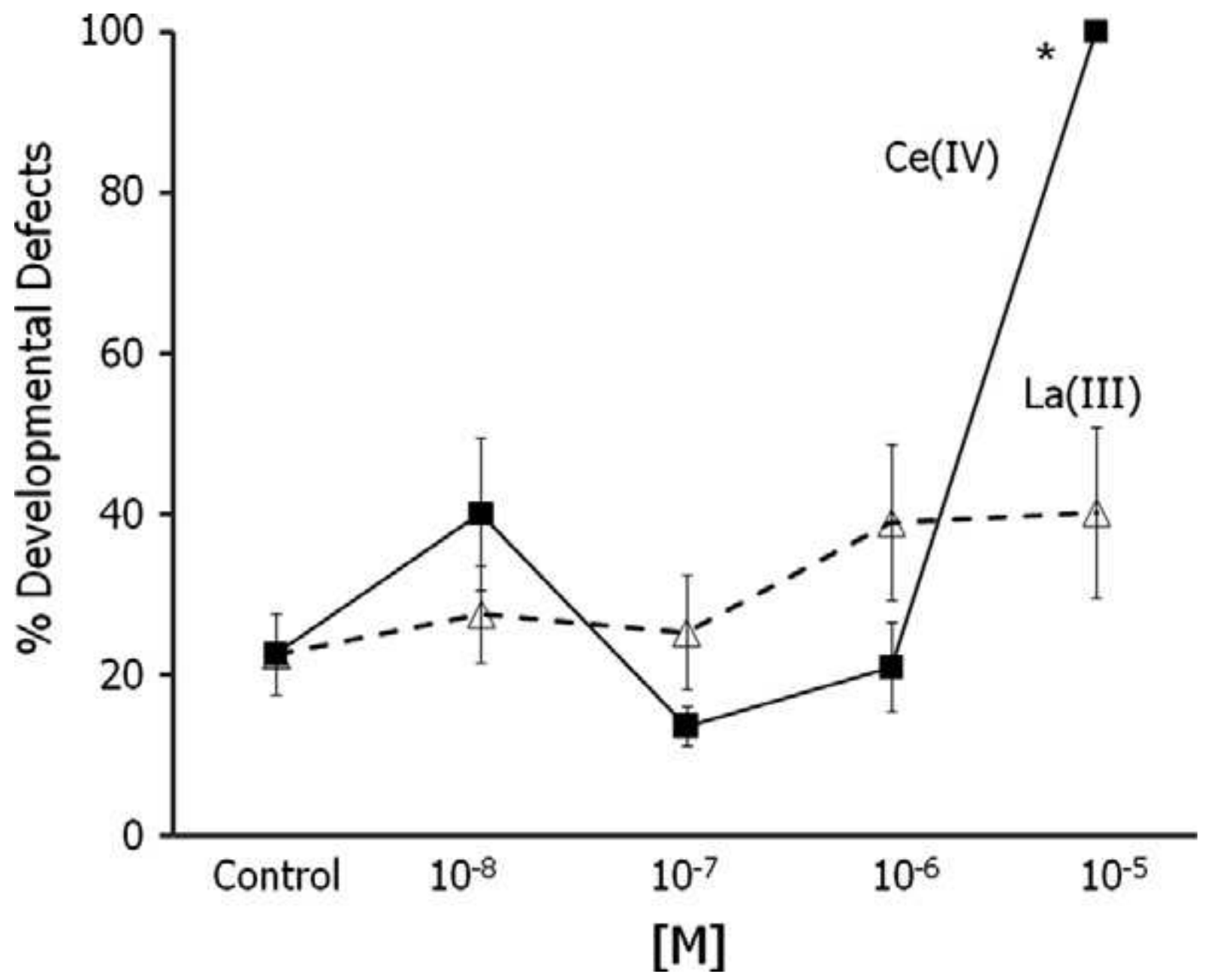

Fig. 5 Percent developmental defects in the offspring of Ce(IV)-exposed sperm (* $p<$ 0.02). No effects were detected following sperm exposure to La(III). 
Table 1. Mean numbers pf mitotic aberrations per embryo in Ce(IV)- vs. La(III)-exposed cleaving P. lividus embryos. Quadruplicate experiment; blank controls were run in 12 replicates; positive controls [Cd(II)-exposed] gave $100 \%$ mitotic arrest. Abbreviations: $B=$ anaphase bridges $; \mathrm{LC}=$ lagging chromosomes; $\mathrm{SC}=$ scattered chromosomes; $\mathrm{MS}=$ multipolar spindles; $\mathrm{TMA}=$ total mitotic aberrations per embryo. Data of other aberrations (acentric fragments, multiple fragmentation) were scanty and not reported.

\begin{tabular}{llllllll}
\hline Treatment & Schedule & No. replicates & B & LC & SC & MS & TMA \\
\hline Blank & & 12 & $0.07 \pm 0.03$ & $0.01 \pm 0.01$ & $0.03 \pm 0.03$ & $0.00 \pm 0.00$ & $0.18 \pm 0.05$ \\
Ce(IV) (M) & $1 \times 10^{-7}$ & 4 & $0.05 \pm 0.03$ & $0.02 \pm 0.02$ & $0.06 \pm 0.02$ & $0.00 \pm 0.00$ & $0.15 \pm 0.10$ \\
& $3 \times 10^{-7}$ & 4 & $0.08 \pm 0.07$ & $0.03 \pm 0.03$ & $0.35 \pm 0.28$ & $0.09 \pm 0.07$ & $0.55 \pm 0.29$ \\
& $1 \times 10^{-6}$ & 4 & $0.06 \pm 0.03$ & $0.01 \pm 0.04$ & $0.21 \pm 0.07$ & $0.10 \pm 0.06$ & $0.37 \pm 0.15$ \\
& $3 \times 10^{-6}$ & 4 & $0.16 \pm 0.14$ & $0.14 \pm 0.10$ & $0.24 \pm 0.11$ & $0.25 \pm 0.09$ & $0.80 \pm 0.11$ \\
& Total & 16 & $0.09 \pm 0.02$ & $0.05 \pm 0.03$ & $0.21 \pm 0.06 *$ & $0.11 \pm 0.05 \S$ & $0.47 \pm 0.14^{*}$ \\
La(III) (M) & $1 \times 10^{-7}$ & 4 & & & & \\
& $3 \times 10^{-7}$ & 4 & $0.06 \pm 0.03$ & $0.06 \pm 0.04$ & $0.05 \pm 0.02$ & $0.00 \pm 0.00$ & $0.15 \pm 0.06$ \\
& $1 \times 10^{-6}$ & 4 & $0.02 \pm 0.00$ & $0.00 \pm 0.00$ & $0.22 \pm 0.12$ & $0.01 \pm 0.01$ & $0.25 \pm 0.19$ \\
& $3 \times 10^{-6}$ & 4 & $0.05 \pm 0.03$ & $0.06 \pm 0.04$ & $0.13 \pm 0.07$ & $0.03 \pm 0.03$ & $0.20 \pm 0.19$ \\
& Total & 16 & $0.11 \pm 0.06$ & $0.02 \pm 0.02$ & $0.05 \pm 0.04$ & $0.00 \pm 0.00$ & $0.12 \pm 0.07$ \\
& & $0.06 \pm 0.02$ & $0.03 \pm 0.01$ & $0.11 \pm 0.04$ & $0.01 \pm 0.01$ & $0.18 \pm 0.03$ \\
\hline
\end{tabular}

